\title{
Associations between changes in oxygenation, dead space and driving pressure induced by the first prone position session and mortality in patients with acute respiratory distress syndrome
}

\begin{abstract}
David M. van Meenen ${ }^{1 \#}$, Jan-Paul Roozeman ${ }^{1 \#}$, Ary Serpa Neto ${ }^{1,2}$, Paolo Pelosi ${ }^{3}$, Marcelo Gama de Abreu ${ }^{4,5}$, Janneke Horn ${ }^{1}$, Olaf L. Cremer ${ }^{6}$, Frederique Paulus ${ }^{1}$, Marcus J. Schultz ${ }^{1,7,8,9}$; for the MARS Consortium*

${ }^{1}$ Department of Intensive Care, Amsterdam University Medical Centers, University of Amsterdam, Amsterdam, The Netherlands; ${ }^{2}$ Department of Critical Care Medicine, Hospital Israelita Albert Einstein, São Paulo, Brazil; ${ }^{3}$ Department of Surgical Sciences and Integrated Diagnostics, IRCCS AOU San Martino IST, University of Genoa, Genoa, Italy; ${ }^{4}$ Pulmonary Engineering Group, ${ }^{5}$ Department of Anesthesiology and Intensive Care Medicine, University Hospital Carl Gustav Carus, Technical University Dresden, Dresden, Germany; ${ }^{6}$ Department of Intensive Care Medicine, University Medical Center Utrecht, Utrecht, The Netherlands; ${ }^{7}$ Laboratory of Experimental Intensive Care and Anesthesiology (L.E.I.C.A), Amsterdam University Medical Centers, University of Amsterdam, Amsterdam, The Netherlands; ${ }^{8}$ Mahidol-Oxford Tropical Medicine Research Unit, Faculty of Tropical Medicine, Mahidol University, Bangkok, Thailand; ${ }^{9}$ Nuffield Department of Medicine, University of Oxford, Oxford, UK

Contributions: (I) Conception and design: DM van Meenen, JP Roozeman, MJ Schultz; (II) Administrative support: DM van Meenen, JP Roozeman; (III) Provision of study materials and patients: J Horn, OL Cremer, F Paulus, MJ Schultz; (IV) Collection and assembly of data: DM van Meenen, JP Roozeman, J Horn, OL Cremer, F Paulus, MJ Schultz; (V) Data analysis and interpretation of data: All authors; (VI) Manuscript writing: All authors; (VII) Final approval of manuscript: All authors.
\end{abstract}

\#These authors contributed equally to the work.

Correspondence to: David M. van Meenen, MD. Department of Intensive Care, Amsterdam University Medical Centers, Location AMC, Meibergdreef 9, Amsterdam, 1105 AZ, The Netherlands. Email: d.m.vanmeenen@amsterdamumc.nl.

Background: Outcome prediction in acute respiratory distress syndrome (ARDS) is challenging, especially in patients with severe hypoxemia. The aim of the current study was to determine the prognostic capacity of changes in $\mathrm{PaO}_{2} / \mathrm{FiO}_{2}$, dead space fraction $\left(\mathrm{V}_{\mathrm{D}} / \mathrm{V}_{\mathrm{T}}\right)$ and respiratory system driving pressure $\left(\Delta \mathrm{P}_{\mathrm{RS}}\right)$ induced by the first prone position (PP) session in patients with ARDS.

Methods: This was a post hoc analysis of the conveniently-sized 'Molecular Diagnosis and Risk Stratification of Sepsis' study (MARS). The current analysis included ARDS patients who were placed in the PP. The primary endpoint was the prognostic capacity of the PP-induced changes in $\mathrm{PaO}_{2} / \mathrm{FiO}_{2}, \mathrm{~V}_{\mathrm{D}} / \mathrm{V}_{\mathrm{T}}$, and $\Delta \mathrm{P}_{\mathrm{RS}}$ for 28-day mortality. $\mathrm{PaO}_{2} / \mathrm{FiO}_{2}, \mathrm{~V}_{\mathrm{D}} / \mathrm{V}_{\mathrm{T}}$, and $\Delta \mathrm{P}_{\mathrm{RS}}$ was calculated using variables obtained in the supine position before and after completion of the first PP session. Receiving operator characteristic curves (ROC) were constructed, and sensitivity, specificity positive and negative predictive value were calculated based on the best cutoffs.

Results: Ninety patients were included; 28-day mortality was 46\%. PP-induced changes in $\mathrm{PaO}_{2} / \mathrm{FiO}_{2}$ and $\mathrm{V}_{\mathrm{D}} / \mathrm{V}_{\mathrm{T}}$ were similar between survivors $v s$. non-survivors [+83 $(+24$ to +137$) v s .+58(+21$ to +113$) \mathrm{mmHg}$, and $-0.06(-0.17$ to +0.05$)$ vs. $-0.08(-0.16$ to +0.08$)$, respectively]. PP-induced changes in $\Delta \mathrm{P}_{\mathrm{RS}}$ were different between survivors $v$ s. non-survivors $\left[-3(-7\right.$ to 2$)$ vs. $0(-3$ to +3$\left.) \mathrm{cmH}_{2} \mathrm{O} ; \mathrm{P}=0.03\right]$. The area under the ROC of PP-induced changes in $\Delta \mathrm{P}_{\mathrm{RS}}$ for mortality, however, was low [0.63 (95\% confidence interval (CI), 0.50

\footnotetext{
* MARS consortium members: Amsterdam University Medical Centers, location AMC, Amsterdam, The Netherlands: Friso M. de Beer, Lieuwe D. Bos, Gerie J. Glas, Janneke Horn, Arie J. Hoogendijk, Roosmarijn T. van Hooijdonk, Mischa A. Huson, Tom van der Poll, Brendon Scicluna, Laura R. Schouten, Marcus J. Schultz, Marleen Straat, Lonneke A. van Vught, Luuk Wieske, Maryse A. Wiewel, and Esther Witteveen.

University Medical Center Utrecht, Utrecht, The Netherlands: Marc J. Bonten, Olaf L. Cremer, Jos F. Frencken, Kirsten van de Groep, Peter M. Klein Klouwenberg, Maria E. Koster-Brouwer, David S. Ong, Meri R. Varkila and Diana M. Verboom.
} 
to 0.75 ]; PP-induced changes in $\Delta \mathrm{P}_{\mathrm{RS}}$ had a sensitivity and specificity of $76 \%$ and $56 \%$, and a positive and negative predictive value of $60 \%$ and $73 \%$.

Conclusions: Changes in $\mathrm{PaO}_{2} / \mathrm{FiO}_{2}, \mathrm{~V}_{\mathrm{D}} / \mathrm{V}_{\mathrm{T}}$, and $\Delta \mathrm{P}_{\mathrm{RS}}$ induced by the first $\mathrm{PP}$ session have poor prognostic capacities for 28-day mortality in ARDS patients.

Keywords: Acute respiratory distress syndrome (ARDS); refractory hypoxemia; prone position (PP); prognostication; mortality; oxygenation; $\mathrm{PaO}_{2} / \mathrm{FiO}_{2}$; dead space; $\mathrm{V}_{\mathrm{D}} / \mathrm{V}_{\mathrm{T}}$; driving pressure; respiratory system driving pressure; $\Delta \mathrm{P} ; \Delta \mathrm{P}_{\mathrm{RS}}$

Submitted May 02, 2019. Accepted for publication Nov 08, 2019.

doi: $10.21037 /$ jtd.2019.12.38

View this article at: http://dx.doi.org/10.21037/jtd.2019.12.38

\section{Introduction}

One randomized clinical trial in patients with moderate to severe acute respiratory distress syndrome (ARDS) convincingly showed mortality benefit from turning patients from the supine to the prone position (PP) (1). Two meta-analyses confirmed the benefit of the PP $(2,3)$, though the PP remains underutilized (4,5). Different mechanisms have been proposed to explain survival benefit induced by repositioning to the $\mathrm{PP}$, including homogenizing of transpleural pressures, decreasing lung stress and strain by increasing lung volumes, and decreasing overdistension by redistribution of lung ventilation.

Outcome prediction in ARDS patients is challenging $(6,7)$, especially in patients with severe refractory hypoxemia in whom PP sessions are often needed. In ARDS patients, the ratio of arterial oxygen partial pressure $\left(\mathrm{PaO}_{2}\right)$ to fractional inspired oxygen $\left(\mathrm{FiO}_{2}\right)$ ratio $\left(\mathrm{PaO}_{2} / \mathrm{FiO}_{2}\right)(8)$, dead space fraction $\left(\mathrm{V}_{\mathrm{D}} / \mathrm{V}_{\mathrm{T}}\right)(9,10)$, and respiratory system driving pressure $\left(\Delta \mathrm{P}_{\mathrm{RS}}\right)(11,12)$ have an association with mortality. Turning a patient from supine to the PP affects $\mathrm{PaO}_{2} / \mathrm{FiO}_{2}, \mathrm{~V}_{\mathrm{D}} / \mathrm{V}_{\mathrm{T}}$ and $\Delta \mathrm{P}_{\mathrm{RS}}$ through various mechanisms, and changes induced by this repositioning could be helpful in outcome prediction $(6,7,13)$. A recent post hoc analysis of the randomized clinical trial (RCT) mentioned above (1) did not confirm this, though (14). It must be mentioned, however, that that analysis only used changes in $\mathrm{PaO}_{2} /$ $\mathrm{FiO}_{2}$ for outcome prediction, and also that changes were calculated from blood gas analysis results after positioning in the PP and before repositioning to the supine position.

The aim of the current analysis, therefore, was to determine the association between PP-induced changes in $\mathrm{PaO}_{2} / \mathrm{FiO}_{2}$, as well as $\mathrm{V}_{\mathrm{D}} / \mathrm{V}_{\mathrm{T}}$ and $\Delta \mathrm{P}_{\mathrm{RS}}$, using ventilation variables collected before placing patients in the $\mathrm{PP}$ and after repositioning to supine, and outcomes. For this purpose, the 'Molecular Diagnosis and Risk stratification of Sepsis' study (MARS), a large cohort study including patients with ARDS needing PP, was reanalyzed. The primary hypothesis tested was that changes in $\mathrm{PaO}_{2}$ / $\mathrm{FiO}_{2}, \mathrm{~V}_{\mathrm{D}} / \mathrm{V}_{\mathrm{T}}$ and $\Delta \mathrm{P}_{\mathrm{RS}}$ induced by the first $\mathrm{PP}$ session have prognostic capacity for mortality.

\section{Methods}

\section{Design and ethical approval}

MARS was a conveniently-sized observational study capturing granular data of intensive care unit (ICU) patients in two Dutch hospitals $(15,16)$. In MARS, detailed demographic and clinical data, including ventilator settings and ventilation variables, as well as outcome data were prospectively collected from ICU admission and start of invasive ventilation, until extubation and ICU discharge, and 1-year mortality. The Institutional Review Board approved the study protocol of the parent study and the use of an opt-out consent procedure (protocol no. 10-056C). MARS was registered at www.clinicaltrials.gov (identifier NCT01905033). The current report adheres to the STROBE guidelines (17).

\section{Patients}

Patients were eligible for participation in MARS if they had an expected length of stay in the ICU of more than 24 hours. MARS itself used no exclusion criteria.

For the purpose of this post hoc analysis, the following additional inclusion criteria were used: (I) admitted to the ICU of the Amsterdam University Medical Centers, location Academic Medical Center (AMC), Amsterdam, The Netherlands; (II) having ARDS; and (III) use of 
the PP for refractory hypoxemia. The single reason for exclusion was impossibility to capture complete sets of variables, necessary for calculating $\mathrm{PaO}_{2} / \mathrm{FiO}_{2}, \mathrm{~V}_{\mathrm{D}} / \mathrm{V}_{\mathrm{T}}$ or $\Delta \mathrm{P}_{\mathrm{RS}}$ before and after the first PP session. Thus, patients who died during the first PP session and patients who were transferred to another hospital while in the PP, were excluded.

\section{ARDS diagnosis}

The MARS team existed of extensively trained clinical researchers who scored all patients prospectively for presence of acute lung injury (ALI) or ARDS according to the American-European Consensus Conference criteria for ARDS (18). Patients were later re-classified using the Berlin Definition for ARDS that was introduced after initiation of the MARS (8). All patients initially diagnosed with ARDS also fulfilled the Berlin definition and could thus be reclassified as having mild, moderate or severe ARDS based on the lowest $\mathrm{PaO}_{2} / \mathrm{FiO}_{2}$ within the first 24 hours after the initial diagnosis of ARDS (8).

\section{Calculation of $\mathrm{PaO}_{2} / \mathrm{FiO}_{2}, V_{D} / V_{T}$ and $\triangle P_{R S}$}

$\mathrm{PaO}_{2}$ was measured using a point-of-care blood gas analyzer (Rapidlab 1265, Siemens Healthcare GmbH, Kemnath, Germany). Continuous end-tidal $\mathrm{CO}_{2}\left(\mathrm{EtCO}_{2}\right)$ monitoring was performed using main-stream capnography (Philips, Best, The Netherlands). $\mathrm{FiO}_{2}$, positive end-expiratory pressure (PEEP) and maximum airway pressure $\left(\mathrm{P}_{\max }\right)$ were recorded from the ventilator at the moment of blood sampling for blood gas analyses.

$\mathrm{PaO}_{2} / \mathrm{FiO}_{2}, \mathrm{~V}_{\mathrm{D}} / \mathrm{V}_{\mathrm{T}}$, and $\Delta \mathrm{P}_{\mathrm{RS}}$ were calculated using variables obtained in the supine position before and after completion of the first PP session. For these calculations, data 1 hour before start, and 1 hour after repositioning to the supine position were used. If these data were missing, we used data closest to the 1-hour time point but never more than 3 hours before start and 3 hours after ending the first $\mathrm{PP}$ session. $\mathrm{PaO}_{2} / \mathrm{FiO}_{2}$ was calculated by dividing $\mathrm{PaO}_{2}$ by $\mathrm{FiO}_{2} \cdot \mathrm{V}_{\mathrm{D}} / \mathrm{V}_{\mathrm{T}}$ was calculated using the modified Bohr formula in which $\mathrm{V}_{\mathrm{D}} / \mathrm{V}_{\mathrm{T}}=\left(\mathrm{PaCO}_{2}-\mathrm{PetCO}_{2}\right) / \mathrm{PaCO}_{2}(7) . \Delta \mathrm{P}_{\mathrm{RS}}$ was calculated by subtracting PEEP from $\mathrm{P}_{\text {max }}$, measured at zero flow.

\section{Primary and secondary endpoints}

The primary endpoint was the prognostic capacity of
$\mathrm{PaO}_{2} / \mathrm{FiO}_{2}, \mathrm{~V}_{\mathrm{D}} / \mathrm{V}_{\mathrm{T}}$ and $\Delta \mathrm{P}_{\mathrm{RS}}$, expressed in the area under the Receiver Operating Characteristic (ROC) for allcause mortality at day 28 . Secondary outcomes were the prognostic capacities of $\mathrm{PaO}_{2} / \mathrm{FiO}_{2}, \mathrm{~V}_{\mathrm{D}} / \mathrm{V}_{\mathrm{T}}$ and $\Delta \mathrm{P}_{\mathrm{RS}}$ for ICU and 1-year mortality. These outcomes should be seen as explorative, and therefore no correction for multiple testing was performed.

\section{The local guideline for ventilatory support}

The local guideline for ventilatory support advised on main ventilator settings in patients with ARDS, and indications for the PP (19). Briefly, ARDS patients were to receive invasive ventilation using a pressure-controlled ventilation mode, or pressure support ventilation mode, with tidal volume targeting $6 \mathrm{ml}$ per kilogram of predicted body weight and PEEP following a 'lower PEEP/FiO table', where every increase in PEEP was to be preceded by a recruitment maneuver. Nurses and physicians adjusted the inspiratory pressure to maintain the correct tidal volume.

Patients were assessed at least three times daily to determine whether weaning could start, consisting of switches to a pressure support mode of ventilation, if not yet spontaneously breathing. If pressure support ventilation was accepted, the level of support was gradually decreased to a minimum of $5 \mathrm{cmH}_{2} \mathrm{O}$ at least three times per day. Tracheal extubation was performed at the discretion of attending physicians, based on general extubation criteria (20).

\section{The local guideline for prone positioning}

The local guideline dictated that $\mathrm{PP}$ sessions were indicated in patients in whom the $\mathrm{PaO}_{2} / \mathrm{FiO}_{2}$ remained $<125 \mathrm{mmHg}$ despite increases in PEEP level $\geq 10 \mathrm{cmH}_{2} \mathrm{O}$ at a minimum $\mathrm{FiO}_{2} \geq 0.6$. Sessions were repeated if $\mathrm{PaO}_{2} / \mathrm{FiO}_{2}$ remained or dropped to $<125 \mathrm{mmHg}$ at a PEEP of $\geq 10 \mathrm{cmH}_{2} \mathrm{O}$ at a minimum $\mathrm{FiO}_{2} \geq 0.6$ when back in the supine position. Of note, the local guidelines for ventilation do not allow changes in PEEP, neither when a patient is in the PP nor before the results of blood gas analyses become available when a patient is returned to supine.

\section{Power calculation}

A formal power calculation was not performed, but instead this analysis used all patients who had received at least one PP session during the 3 years MARS enrolled patients. 


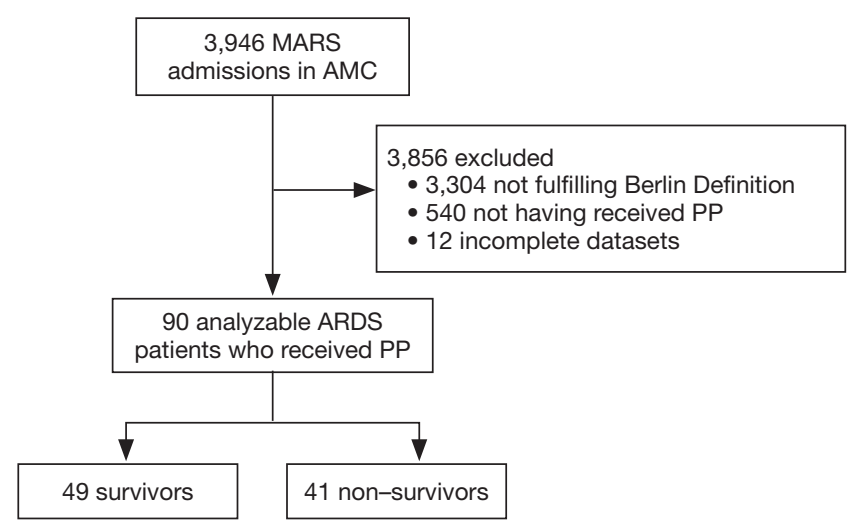

Figure 1 Patient flowchart. AMC, Amsterdam University Medical Centers, location Academic Medical Center.

\section{Analysis plan}

Variables and parameters were expressed as medians [25th to 75 th interquartile range (IQR) for continuous variables, or percentages for categorical variables. Continuous variables and parameters were analyzed using a Mann-Whitney $\mathrm{U}$-test or a Welch two-ample $t$-test, and proportions were compared using a Fisher exact test.

First, absolute and relative changes between $\mathrm{PaO}_{2} / \mathrm{FiO}_{2}$, $\mathrm{V}_{\mathrm{D}} / \mathrm{V}_{\mathrm{T}}$ and $\Delta \mathrm{P}_{\mathrm{RS}}$ before to after the first PP session were calculated and compared between 28-day survivors and nonsurvivors using the Mann-Whitney $\mathrm{U}$-test. The association between PP-induced changes in $\mathrm{PaO}_{2} / \mathrm{FiO}_{2}, \mathrm{~V}_{\mathrm{D}} / \mathrm{V}_{\mathrm{T}}$, and $\Delta \mathrm{P}_{\mathrm{RS}}$, and mortality was determined using a univariate and multivariable logistic regression. A propensity score was entered into the multivariate model as a covariate to correct for disease severity and other baseline factors that could have influenced patient outcome (21), using the following predefined baseline variables: disease severity [age, an age-corrected Acute Physiology and Chronic Health Evaluation (APACHE) IV score], and baseline $\mathrm{PaO}_{2} / \mathrm{FiO}_{2}$, $\mathrm{V}_{\mathrm{D}} / \mathrm{V}_{\mathrm{T}}, \Delta \mathrm{P}_{\mathrm{RS}}, \mathrm{V}_{\mathrm{T}}$, and respiratory rate (RR). These variables were selected because they are all suggested to have an association with mortality. As there were 41 events of the outcome of interest, i.e., 28-day mortality, and the general rule of thumb is that 10 events of the outcome of interest are required for each variable entered in the model (22), the multivariable analysis using only 2 variables can be seen as sufficiently powered. An etiological model was chosen because of the restricted sample size.

Second, area under the ROC curve for 28-day mortality was calculated for PP-induced changes in $\mathrm{PaO}_{2} / \mathrm{FiO}_{2}, \mathrm{~V}_{\mathrm{D}} / \mathrm{V}_{\mathrm{T}}$ and $\Delta \mathrm{P}_{\mathrm{RS}}$. The optimal cutoff was determined using the
Youden index (23), and sensitivity, specificity, and positive and negative predictive values were calculated. A priori, an area under the curve (AUC) of $\leq 0.6$ was considered 'poor', 0.6-0.7 'fair', 0.7-0.8 'good', 0.8-0.9 'very good' and $\geq 0.9$ 'excellent' (24).

Statistical analyses were performed using $\mathrm{R}$ and the R-studio interface ( $\mathrm{R}$ version 3.0, www.r-project.org). A P value $<0.05$ was considered as statistically significant.

\section{Results}

\section{Patients}

Of 3,946 patients enrolled in MARS in the participating center, $642(16 \%)$ patients were diagnosed with ARDS (Figure 1). Of these, 102 (16\%) patients were repositioned in the PP for at least one session. After exclusion of patients with incomplete datasets, 90 patients remained in the analysis. Baseline demographics, ventilation variables, and ventilations parameters before and after the first PP session are presented in Tables 1,2. All cause 28-day mortality rate was $46 \%$. Patients who died were sicker according to the APACHE IV scores. Patients who died had higher $\mathrm{V}_{\mathrm{D}} / \mathrm{V}_{\mathrm{T}}$ at baseline, while baseline $\mathrm{PaO}_{2} / \mathrm{FiO}_{2}$ and $\Delta \mathrm{P}_{\mathrm{RS}}$ were not different between survivors and non-survivors. Patients with ARDS in MARS study who did not meet the criteria for and thus were not placed in the PP had similar baseline characteristics but were less sick according to the median APACHE IV score (Table S1). Time between start of invasive ventilation and the first PP session, total duration of the first PP session, and the total number of PP sessions during the entire ICU stay were not different between survivors and non-survivors (Table S2). In 90\% and 96\% of cases, data to calculate the parameters of interest were available within the last hour before the first PP session, and the first hour after repositioning to supine, respectively.

\section{$P P$-induced changes in $\mathrm{PaO}_{2} / \mathrm{FiO}_{2}, V_{D} / V_{T}$ and $\Delta P_{R S}$}

The first PP session resulted in a rise in $\mathrm{PaO}_{2} / \mathrm{FiO}_{2}$ that persisted after the patient was repositioned back in the supine position in $90 \%$ of the cases, and a decrease in $\mathrm{V}_{\mathrm{D}} /$ $\mathrm{V}_{\mathrm{T}}$ and $\Delta \mathrm{P}_{\mathrm{RS}}$ in $66 \%$ and $56 \%$, respectively (Figure 2 and Table 2).

\section{Survivors versus non-survivors}

PP-induced changes in $\mathrm{PaO}_{2} / \mathrm{FiO}_{2}$ and $\mathrm{V}_{\mathrm{D}} / \mathrm{V}_{\mathrm{T}}$ were not 
Table 1 Baseline characteristics

\begin{tabular}{|c|c|c|c|}
\hline Characteristics & Survivors $(\mathrm{N}=49)$ & Non-survivors $(\mathrm{N}=41)$ & $\mathrm{P}$ \\
\hline Age, median [IQR], years & 55 [44 to 65$]$ & $58[50$ to 66$]$ & 0.59 \\
\hline Weight, median [IQR], kg & 80 [73 to 90$]$ & 75 [62 to 89] & 0.16 \\
\hline PBW, median [IQR] & $66[63$ to 72$]$ & 71 [56 to 80$]$ & 0.65 \\
\hline APACHE IV, median [IQR] & $61[50$ to 86$]$ & $91[75$ to 110$]$ & $<0.001$ \\
\hline \multicolumn{4}{|c|}{ Reasons for ICU admission, n [\%] } \\
\hline Surgical & 13 [27] & 12 [29] & 0.77 \\
\hline Pneumonia & 17 [35] & $11[27]$ & 0.42 \\
\hline Other & $13[27]$ & 13 [32] & 0.59 \\
\hline \multicolumn{4}{|l|}{ Causes of ARDS, $n$ [\%] } \\
\hline Sepsis & $9[18]$ & 10 [24] & 0.48 \\
\hline Pneumonia & $31[63]$ & 19 [46] & 0.17 \\
\hline Trauma & $6[12]$ & $6[15]$ & 0.74 \\
\hline Aspiration & $1[2]$ & 5 [12] & 0.05 \\
\hline Cardiac arrest & $1[2]$ & $1[2]$ & 0.89 \\
\hline Transfusion & 1 [2] & $0[0]$ & 0.71 \\
\hline
\end{tabular}

Baseline characteristics for all patients, survivors and non-survivors. Values are expressed in percentages (\%) of total patients in the group or median with interquartile ranges [IQR], where applicable. kg, kilogram; PBW, predicted body weight; BMI, body mass index; APACHE, acute physiology and chronic health evaluation; ICU, intensive care unit; ARDS, acute respiratory distress syndrome.

different between survivors and non-survivors. PP-induced changes in $\Delta \mathrm{P}_{\mathrm{RS}}$, though, were different between survivors and non-survivors (Figure 2 and Table S3). In the univariate logistic regression, only the absolute $\mathrm{PP}$-induced change in $\Delta \mathrm{P}_{\mathrm{RS}}$, and the absolute and relative change in arterial $\mathrm{pH}$ induced by the first PP session showed an association with 28-day mortality (Table S4). These associations did not sustain in the multivariate analysis when corrected for the propensity score.

After repositioning back in the supine position, differences were also noted in arterial $\mathrm{pH}$ between survivors and non-survivors (Table S3).

\section{Prognostic value of PP-induced changes in $\mathrm{PaO}_{2} / \mathrm{FiO}_{2}, V_{D} /$ $V_{T}$ and $\triangle P_{R S}$}

Prognostic characteristics of absolute and relative changes in induced by the first $\mathrm{PP}$ session are shown in Table 3. Only the absolute $\mathrm{PP}$-induced change in $\Delta \mathrm{P}_{\mathrm{RS}}$ had prognostic capacity, all other $\mathrm{PP}$-induced changes performed poorly. The prognostic capacity for ICUmortality and 1-year mortality of PP-induced changes were also poor (Table S5,S6).

\section{Discussion}

The findings of this post hoc analysis of MARS can best be summarized as follows: (I) PP-induced changes in $\mathrm{PaO}_{2} / \mathrm{FiO}_{2}$ and $\mathrm{V}_{\mathrm{D}} / \mathrm{V}_{\mathrm{T}}$ are not different between survivors and non-survivors; (II) $\mathrm{PP}$-induced changes in $\Delta \mathrm{P}_{\mathrm{RS}}$ are different between survivors and non-survivors, but the association with outcome is not independent; and (III) prognostic capacity for mortality of $\mathrm{PP}$-induced changes in oxygenation and lung mechanics is insufficient for use in 
Table 2 Ventilation variables and parameters

\begin{tabular}{|c|c|c|c|c|c|c|}
\hline $\begin{array}{l}\text { Variables and } \\
\text { parameters }\end{array}$ & \multicolumn{3}{|c|}{ Before the first PP session } & \multicolumn{3}{|c|}{ After the first PP session } \\
\hline $\mathrm{V}_{\mathrm{T}}, \mathrm{mL} / \mathrm{kg}$ PBW & $6.5[5.8$ to 6.9$]$ & $6.2[5.1$ to 6.5$]$ & 0.18 & $6.4[6.0$ to 7.0$]$ & $6.5[5.5$ to 8.0$]$ & 0.97 \\
\hline PEEP, $\mathrm{cmH}_{2} \mathrm{O}$ & 15 [10 to 16$]$ & $15[11$ to 16$]$ & 0.77 & 15 [12 to 16$]$ & 15 [14 to 18$]$ & 0.05 \\
\hline $\mathrm{P}_{\max }, \mathrm{cmH}_{2} \mathrm{O}$ & 32 [26 to 39$]$ & 35 [29 to 40$]$ & 0.22 & 31 [29 to 36$]$ & 36 [33 to 38$]$ & 0.04 \\
\hline $\mathrm{PaO}_{2}, \mathrm{mmHg}$ & 66 [59 to 80$]$ & $65[60$ to 77$]$ & 0.64 & $92[72$ to 122$]$ & 85 [69 to 110$]$ & 0.29 \\
\hline $\mathrm{PaCO}_{2}, \mathrm{mmHg}$ & $50[39$ to 58$]$ & 47 [42 to 62$]$ & 0.52 & 44 [38 to 50$]$ & 47 [35 to 56$]$ & 0.77 \\
\hline $\mathrm{HCO}_{3}^{-}, \mathrm{mmol} / \mathrm{L}$ & 24 [21 to 27$]$ & 22 [19 to 26$]$ & 0.07 & 24 [21 to 28$]$ & 22 [18 to 26$]$ & 0.02 \\
\hline $\mathrm{pH}$ & $7.32[7.26$ to 7.39$]$ & $7.25[7.17$ to 7.33$]$ & 0.02 & 7.39 [7.33 to 7.42$]$ & $7.31[7.20$ to 7.40$]$ & 0.01 \\
\hline$\Delta \mathrm{P}_{\mathrm{RS}}, \mathrm{cmH}_{2} \mathrm{O}$ & 18 [14 to 24$]$ & 20 [15 to 24$]$ & 0.44 & $17[12$ to 21$]$ & 19 [16 to 24$]$ & 0.03 \\
\hline
\end{tabular}

Variables and parameters before and after the first PP session. Data are expressed as median with IQR. VT, tidal volume; PBW, predicted body weight; $\mathrm{PEEP}$, positive end-expiratory pressure; $\mathrm{P}_{\max }$, maximum airway pressure; $\mathrm{FiO}_{2}$, fraction of inspired oxygen; $\mathrm{PaO} \mathrm{O}_{2}$, arterial oxygen tension; $\mathrm{PaCO}_{2}$, arterial carbon dioxide tension; $\mathrm{HCO}_{3}{ }^{-}$, arterial bicarbonate; $\mathrm{PaO}_{2} / \mathrm{FiO}_{2}$, ratio of arterial oxygen tension to fraction of inspired oxygen; VD/VT, dead space fraction; $\Delta \mathrm{P}_{\mathrm{RS}}$, respiratory system driving pressure.

clinical practice.

This is the first study that investigated the prognostic capacities of PP-induced changes in oxygenation, dead space and respiratory system mechanics for outcome prediction in ARDS patients. One strength of this study is that trained researchers collected data used for the calculation of $\mathrm{PaO}_{2} /$ $\mathrm{FiO}_{2}, \mathrm{~V}_{\mathrm{D}} / \mathrm{V}_{\mathrm{T}}$ and $\Delta \mathrm{P}_{\mathrm{RS}}$. In addition, these researchers were also extensively trained in using the diagnostic criteria for ARDS. MARS ran in a tertiary hospital, recruiting a broad selection of ARDS patients, increasing its external validity. Also, different from a recent post hoc analysis of the PROSEVA trial (1), in the current analysis we prevented 'contamination' of the early effects of repositioning a patient in the PP by using data from before the first PP session. We also focused on sustained effects of the first PP session, and therefore only used data after repositioning to supine. We consider this is a fairer interpretation of PPinduced changes in gas exchange and lung mechanics.

Though the PP has many benefits, it is still uncertain how ventilation mechanics are exactly altered during repositioning patients from the supine position to the PP, and whether they remain altered after repositioning back to the supine position. Recruitment of lung tissue, changes in intra-abdominal pressures, and chest wall and lung compliances have not been studied well in ARDS patients in the PP, and the exact physiological mechanisms remained uncertain so far. Factors such as weight and pressure relocation, compliance changes, changes in chest wall shape, perfusion and ventilation redistribution have been thought to be contributing factors (25). Even though lung compliance is known to improve in general during a PP session, this does not always happen (25).

While $\mathrm{PaO}_{2} / \mathrm{FiO}_{2}$ is used for risk classification in the Berlin Definition, the results of this current study did not find a difference between survivors and non-survivors. This may not be too surprising as the study included patients with more severe ARDS, in which mortality is highest. However, there was also no association between PPinduced changes in $\mathrm{PaO}_{2} / \mathrm{FiO}_{2}$ and outcome. This is in line with a previous study investigating the predictive value of $\mathrm{PP}$-induced changes in $\mathrm{PaO}_{2} / \mathrm{FiO}_{2}(14,26)$. In that study, mortality rates were similar for 'responders' and 'nonresponders', based on changes in $\mathrm{PaO}_{2} / \mathrm{FiO}_{2}$.

In line with a previous investigation (27), $\mathrm{V}_{\mathrm{D}} / \mathrm{V}_{\mathrm{T}}$ before the first PP session was lower in survivors compared to nonsurvivors. Indeed, in that previous study it was shown that higher $\mathrm{V}_{\mathrm{D}} / \mathrm{V}_{\mathrm{T}}$ is associated with worse outcome in ARDS patients. 

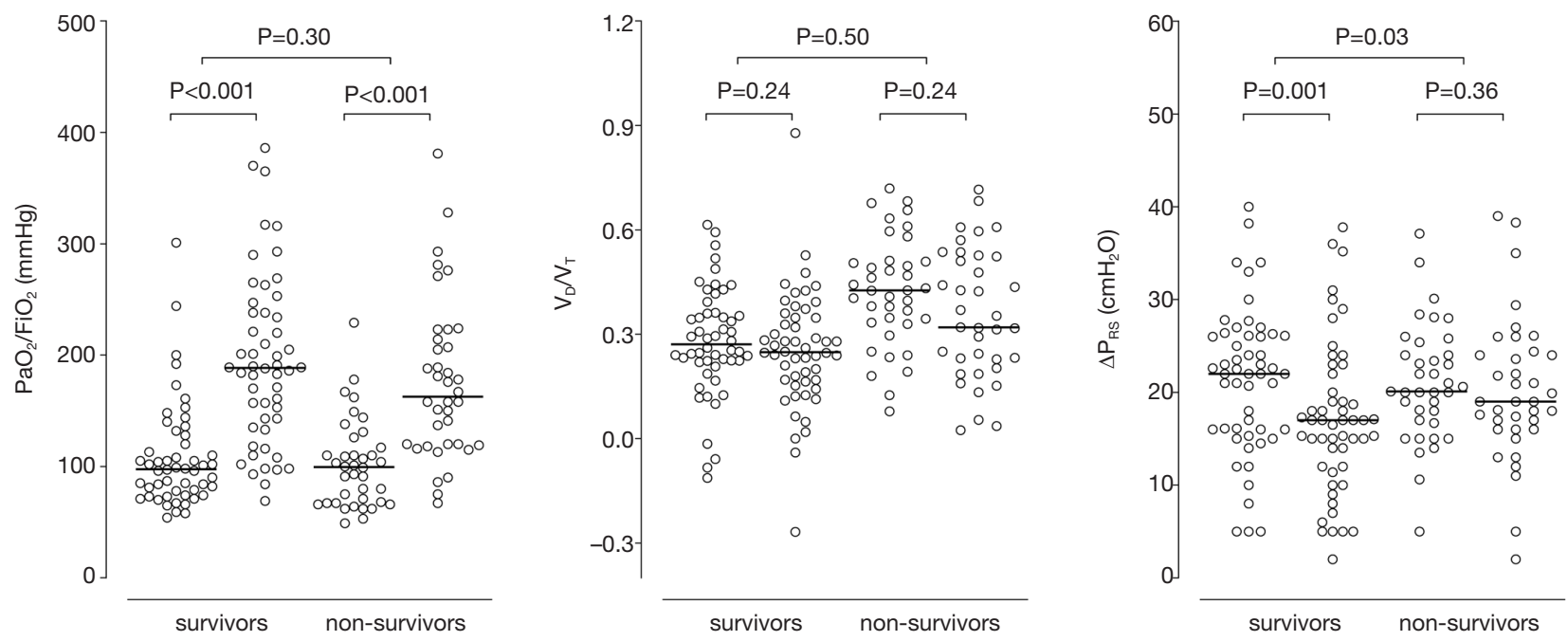

Figure 2 PP-induced changes in $\mathrm{PaO}_{2} / \mathrm{FiO}_{2}, \mathrm{~V}_{\mathrm{D}} / \mathrm{V}_{\mathrm{T}}$ and $\Delta \mathrm{P}_{\mathrm{RS}}$. Dots represent individual $\mathrm{PaO}_{2} / \mathrm{FiO}_{2}, \mathrm{~V}_{\mathrm{D}} / \mathrm{V}_{\mathrm{T}}$ and $\Delta \mathrm{P}_{\mathrm{RS}}$ calculated using data collected closest to start, and as early as possible after the first PP session. Horizontal lines are medians. $\mathrm{PaO}_{2} / \mathrm{FiO}_{2}$, ratio between arterial oxygen tension and fraction of inspired oxygen; $V_{\mathrm{D}} / \mathrm{V}_{\mathrm{T}}$, dead space fraction; $\Delta \mathrm{P}_{\mathrm{RS}}$, respiratory system driving pressure.

Table 3 Prognostic capacities of changes induced by the first PP session

\begin{tabular}{|c|c|c|c|c|c|c|}
\hline Parameters & AUROC (95\% Cl) & Best cutoff & Sensitivity (95\% Cl) (\%) & Specificity $(95 \% \mathrm{Cl})(\%)$ & PPV (\%) & NPV (\%) \\
\hline $\mathrm{PaO}_{2} / \mathrm{FiO}_{2}$ & 0.55 (0.43 to 0.67 ) & $+68 \mathrm{mmHg}$ & 59 (42 to 74$)$ & 60 (45 to 74$)$ & 56 & 63 \\
\hline $\mathrm{V}_{\mathrm{D}} / \mathrm{V}_{\mathrm{T}}$ & 0.51 (0.39 to 0.63 ) & -0.10 & 46 (31 to 63 ) & 65 (50 to 78 ) & 53 & 58 \\
\hline$\Delta \mathrm{P}_{\mathrm{RS}}$ & 0.63 (0.51 to 0.75$)$ & $-3 \mathrm{cmH}_{2} \mathrm{O}$ & 76 (60 to 88$)$ & 56 (41 to 71$)$ & 60 & 73 \\
\hline $\mathrm{PaO}_{2} / \mathrm{FiO}_{2}$ & 0.55 (0.43 to 0.67$)$ & $+78 \%$ & 63 (47 to 78$)$ & 54 (39 to 69$)$ & 54 & 63 \\
\hline $\mathrm{V}_{\mathrm{D}} / \mathrm{V}_{\mathrm{T}}$ & 0.51 (0.39 to 0.63$)$ & $-46 \%$ & 88 (74 to 96$)$ & 31 (19 to 46$)$ & 52 & 75 \\
\hline$\Delta \mathrm{P}_{\mathrm{RS}}$ & 0.62 (0.50 to 0.73$)$ & $-14 \%$ & 76 (60 to 88$)$ & 50 (35 to 65$)$ & 56 & 71 \\
\hline
\end{tabular}

AUROC, area under the receiver operator characteristics curve; PPV, positive predictive value; NPV, negative predictive value; CI, confidence interval; $\mathrm{PaO}_{2} / \mathrm{FiO}_{2}$, ratio between arterial oxygen tension and fraction of inspired oxygen; $\mathrm{V}_{\mathrm{D}} / \mathrm{V}_{\mathrm{T}}$, dead space fraction; $\Delta \mathrm{P}_{\mathrm{RS}}$, respiratory system driving pressure.

Several recent reports showed an association between $\Delta \mathrm{P}_{\mathrm{RS}}$ and outcome of ARDS patients $(11,12,28)$. The $\Delta \mathrm{P}_{\mathrm{RS}}$ has even been suggested as one of the most important ventilation parameters predicting outcome $(4,11,29,30)$. The results of this current study add to this understanding with the finding that $\mathrm{PP}$-induced changes in $\Delta \mathrm{P}_{\mathrm{RS}}$ were significantly different between survivors and non-survivors. Changes in $\Delta \mathrm{P}_{\mathrm{RS}}$ induced by the first $\mathrm{PP}$ session, however, remain to have a disappointing low prognostic capacity. Of note, in all patients $\mathrm{PP}$-induced changes in $\Delta \mathrm{P}_{\mathrm{RS}}$ resulted from a change in $\mathrm{P}_{\text {plat }}$. This can be explained by the fact that the local guidelines for ventilation do not allow changes in PEEP during PP.

In some patients $\mathrm{PaO}_{2} / \mathrm{FiO}_{2}$ could have improved beyond the value that triggered the decision to start a PP session. This explains why the $\mathrm{PaO}_{2} / \mathrm{FiO}_{2}$ in the last hour before the first $\mathrm{PP}$ session was higher than the $\mathrm{PaO}_{2} / \mathrm{FiO}_{2}$ that triggered the team to initiate the first $\mathrm{PP}$ session, in line with the local guideline for invasive ventilation. Indeed, in between these two-time points changes, and even 
improvements in $\mathrm{PaO}_{2} / \mathrm{FiO}_{2}$ are likely to occur, e.g., due to PEEP titrations or recruitment maneuvers. This finding is in line with what was found in the latest randomized clinical trial of the PP (1).

There are several reasons why we had to reject the hypothesis, apart from the realistic possibility that changes in oxygenation and lung mechanics induced by the first PP session may not be associated with outcome. The sample size of this study was relatively small, and hereby possibly not able to detect the prognostic capacity. It is also possible that changes in PEEP during the first PP session affected the PP-induced changes in the parameters of interest. The findings of the present study may also be seen in light of finding of other studies in which 'improvements' in physiologic parameters did not translate in better outcomes, or vice versa. For instance, the seminal RCT comparing low $v s$. high tidal volumes showed ventilation with a low tidal volume to improve survival, but to worsen oxygenation (31). More recently, a randomized clinical trial of high PEEP and recruitment maneuvers showed the intervention to improve oxygenation and even driving pressure, but to worsen outcome (32). We cannot exclude a similar difference between changes in physiologic parameters and outcomes for positioning in the PP.

This study has several limitations. First, the results must be seen as those from a post hoc analysis. The relative low sample size could limit the generalizability of this analysis. However, the values included in the $95 \%$ CI of our primary endpoint (i.e., the AUROC) do not suggest a type II error. It was not possible to determine whether or not patients had received additional recruitment maneuvers during the first PP session, as this was not routinely captured in the database of MARS. Also, esophageal pressure measurements were not performed routinely, and therefore the pulmonary $\Delta \mathrm{P}$ could not be calculated. Because patients were exclusively under pressure-controlled ventilation, $\mathrm{P}_{\max }$ instead of $\mathrm{P}_{\text {plat }}$ was used, as suggested previously (33-35). Furthermore, severity of illness scores like APACHE scores and SAPS have robust prognostic capacities, and thus should be held in consideration when investigating the prognostic capacities of the parameters of interest in this study. However, the multivariate analysis adjusted for a propensity score calculated from age, an age-corrected APACHE IV, and baseline $\mathrm{PaO}_{2} / \mathrm{FiO}_{2}, \mathrm{~V}_{\mathrm{D}} /$ $\mathrm{V}_{\mathrm{T}}, \Delta \mathrm{P}_{\mathrm{RS}}, \mathrm{V}_{\mathrm{T}}$, and the respiratory rate, also failed to find an association between changes in the parameters and outcomes. Finally, the study focused on the first PP session and not successive sessions.

\section{Conclusions}

In conclusion, in this cohort of ARDS patients the first PP session induced changes in $\mathrm{PaO}_{2} / \mathrm{FiO}_{2}, \mathrm{~V}_{\mathrm{D}} / \mathrm{V}_{\mathrm{T}}$, and $\Delta \mathrm{P}_{\mathrm{RS}}$. Only changes in $\Delta \mathrm{P}_{\mathrm{RS}}$ were different between survivors and non-survivors. Neither the change in $\mathrm{PaO}_{2} / \mathrm{FiO}_{2}$ and $\mathrm{V}_{\mathrm{D}} / \mathrm{V}_{\mathrm{T}}$, nor in $\Delta \mathrm{P}_{\mathrm{RS}}$ induced by the first $\mathrm{PP}$ session had sufficient prognostic capacities for outcome.

\section{Acknowledgments}

Funding: This work was supported by the Center for Translational Molecular Medicine (www.ctmm.nl) (grant 041201).

\section{Footnote}

Conflicts of Interest: The authors have no conflicts of interest to declare.

Etbical Statement: The authors are accountable for all aspects of the work in ensuring that questions related to the accuracy or integrity of any part of the work are appropriately investigated and resolved. The Institutional Review Board approved the study protocol of the parent study and the use of an opt-out consent procedure (protocol no. 10-056C).

\section{References}

1. Guérin C, Reignier J, Richard JC, et al. Prone Positioning in the Acute Respiratory Distress Syndrome. N Engl J Med 2013;369:980-1.

2. Beitler JR, Shaefi S, Montesi SB, et al. Prone positioning reduces mortality from acute respiratory distress syndrome in the low tidal volume era: a meta-analysis. Intensive Care Med 2014;40:332-41.

3. Munshi L, Del Sorbo L, Adhikari NKJ, et al. Prone Position for Acute Respiratory Distress Syndrome. A Systematic Review and Meta-Analysis. Ann Am Thorac Soc 2017;14:S280-8.

4. Bellani G, Laffey JG, Pham T, et al. Epidemiology, Patterns of Care, and Mortality for Patients With Acute Respiratory Distress Syndrome in Intensive Care Units in 50 Countries. JAMA 2016;315:788-800.

5. Guérin C, Beuret P, Constantin JM, et al. A prospective international observational prevalence study on prone positioning of ARDS patients: the APRONET (ARDS 
Prone Position Network) study. Intensive Care Med 2018;44:22-37.

6. Gattinoni L, Tognoni G, Pesenti A, et al. Effect of prone positioning on the survival of patients with acute respiratory failure. N Engl J Med 2001;345:568-73.

7. Kallet RH, Zhuo H, Liu KD, et al. The Association Between Physiologic Dead-Space Fraction and Mortality in Subjects With ARDS Enrolled in a Prospective MultiCenter Clinical Trial. Respir Care 2014;59:1611-8.

8. The ARDS Definition Task Force. Acute Respiratory Distress Syndrome: The Berlin Definition. JAMA 2012;307:2526-33.

9. Raurich JM, Vilar M, Colomar A, et al. Prognostic value of the pulmonary dead-space fraction during the early and intermediate phases of acute respiratory distress syndrome. Respir Care 2010;55:282-7.

10. Lucangelo U, Bernabè F, Vatua $S$, et al. Prognostic value of different dead space indices in mechanically ventilated patients with acute lung injury and ARDS. Chest 2008;133:62-71.

11. Amato MBP, Meade MO, Slutsky AS, et al. Driving Pressure and Survival in the Acute Respiratory Distress Syndrome. N Engl J Med 2015;372:747-55.

12. Laffey JG, Bellani G, Pham T, et al. Potentially modifiable factors contributing to outcome from acute respiratory distress syndrome: the LUNG SAFE study. Intensive Care Med 2016;42:1865-76.

13. Gattinoni L, Pesenti A, Carlesso E. Body position changes redistribute lung computed-tomographic density in patients with acute respiratory failure: impact and clinical fallout through the following 20 years. Intensive Care Med 2013;39:1909-15.

14. Albert RK, Keniston A, Baboi L, et al. Prone positioninduced improvement in gas exchange does not predict improved survival in the acute respiratory distress syndrome. Am J Respir Crit Care Med 2014;189:494-6.

15. Klein Klouwenberg PMC, Ong DSY, Bos LDJ, et al. Interobserver agreement of Centers for Disease Control and Prevention criteria for classifying infections in critically ill patients. Crit Care Med 2013;41:2373-8.

16. Bos LD, Cremer OL, Ong DS, et al. External validation confirms the legitimacy of a new clinical classification of ARDS for predicting outcome. Intensive Care Med 2015;41:2004-5.

17. von Elm E, Altman DG, Egger M, et al. The Strengthening the Reporting of Observational Studies in Epidemiology (STROBE) statement: guidelines for reporting observational studies. Lancet 2007;370:1453-7.
18. Bernard GR, Artigas A, Brigham KL, et al. The American-European Consensus Conference on ARDS. Definitions, mechanisms, relevant outcomes, and clinical trial coordination. Am J Respir Crit Care Med 1994;149:818-24.

19. Schultz MJ, de Pont AC. Prone or PEEP, PEEP and prone. Intensive Care Med 2011;37:366-7.

20. Determann RM, Royakkers A, Wolthuis EK, et al. Ventilation with lower tidal volumes as compared with conventional tidal volumes for patients without acute lung injury: a preventive randomized controlled trial. Critical Care 2010;14:R1.

21. Haukoos JS, Lewis RJ. The Propensity Score. JAMA 2015;314:1637-8.

22. Peduzzi P, Concato J, Kemper E, et al. A simulation study of the number of events per variable in logistic regression analysis. J Clin Epidemiol 1996;49:1373-9.

23. Youden WJ. Index for rating diagnostic tests. Cancer 1950;3:32-5.

24. Hajian-Tilaki K. Receiver Operating Characteristic (ROC) Curve Analysis for Medical Diagnostic Test Evaluation. Caspian J Intern Med 2013;4:627-35.

25. Pelosi P, Tubiolo D, Mascheroni D, et al. Effects of the Prone Position on Respiratory Mechanics and Gas Exchange during Acute Lung Injury. Am J Respir Crit Care Med 1998;157:387-93.

26. Gattinoni L, Vagginelli F, Carlesso E, et al. Decrease in $\mathrm{PaCO} 2$ with prone position is predictive of improved outcome in acute respiratory distress syndrome. Crit Care Med 2003;31:2727-33.

27. Nuckton TJ, Alonso JA, Kallet RH, et al. Pulmonary dead-spae fraction as a risk factor for death in the acute respiratory distress syndrome. $\mathrm{N}$ Engl J Med 2002;346:1281-6.

28. Amato MB, Barbas CS, Medeiros DM, et al. Effect of a protective-ventilation strategy on mortality in the acute respiratory distress syndrome. N Engl J Med 1998;338:347-54.

29. Neto AS, Hemmes SNT, Barbas CSV, et al. Association between driving pressure and development of postoperative pulmonary complications in patients undergoing mechanical ventilation for general anaesthesia: a meta-analysis of individual patient data. Lancet Respir Med 2016;4:272-80.

30. Bugedo G, Retamal J, Bruhn A. Driving pressure: a marker of severity, a safety limit, or a goal for mechanical ventilation? Crit Care 2017;21:199.

31. The ARDS Network. Ventilation with Lower Tidal 
Volumes as Compared with Traditional Tidal Volumes for Acute Lung Injury and the Acute Respiratory Distress Syndrome. N Engl J Med 2000;14:343:813.

32. Cavalcanti AB, Suzumura ÉA, Laranjeira LN, et al. Effect of Lung Recruitment and Titrated Positive EndExpiratory Pressure (PEEP vs Low PEEP on Mortality in Patients Witch Acute Respiratory Distress Syndrome: A Randomized Clinical Trial. JAMA 2017;318:1335-45. 33. Bos LD, Schouten LR, Cremer OL, et al. External

Cite this article as: van Meenen DM, Roozeman JP, Serpa Neto A, Pelosi P, Gama de Abreu M, Horn J, Cremer OL, Paulus F, Schultz MJ; for the MARS Consortium. Associations between changes in oxygenation, dead space and driving pressure induced by the first prone position session and mortality in patients with acute respiratory distress syndrome. J Thorac Dis 2019;11(12):5004-5013. doi: 10.21037/jtd.2019.12.38 validation of the APPS, a new and simple outcome prediction score in patients with the acute respiratory distress syndrome. Ann Intensive Care 2016;6:89.

34. Chatburn RL, Volsko TA. Documentation issues for mechanical ventilation in pressure-control modes. Respir Care 2010;55:1705-16.

35. Becher T, van der Staay M, Schädler D, et al. Calculation of mechanical power for pressure-controlled ventilation. Intensive Care Med 2019;45:1321-3. 


\section{Supplementary}

Table S1 Baseline characteristics of ARDS who did not meet the criteria for the PP

\begin{tabular}{|c|c|c|c|}
\hline Characteristics & Survivors ( $N=378$ ) & Non-survivors ( $\mathrm{N}=162)$ & $P$ \\
\hline Age, median [IQR], years & $61[52$ to 71$]$ & $63[53$ to 72$]$ & 0.43 \\
\hline Weight, median [IQR], kg & 80 [70 to 90$]$ & 73 [65 to 87$]$ & 0.02 \\
\hline PBW, median [IQR] & 65 [62 to 72$]$ & 72 [58 to 80$]$ & 0.06 \\
\hline APACHE IV, median [IQR] & 57 [49 to 84] & 80 [63 to 109$]$ & $<0.001$ \\
\hline \multicolumn{4}{|c|}{ Reasons for ICU admission, n [\%] } \\
\hline Surgical & 126 [33] & 37 [23] & 0.01 \\
\hline Pneumonia & $128[34]$ & $55[34]$ & 0.98 \\
\hline Other & 79 [21] & $47[29]$ & 0.04 \\
\hline \multicolumn{4}{|l|}{ Causes of ARDS, $n$ [\%] } \\
\hline Sepsis & $73[19]$ & 36 [22] & 0.44 \\
\hline Pneumonia & 236 [62] & $83[51]$ & $<0.001$ \\
\hline Trauma & $28[7]$ & $31[19]$ & 0.37 \\
\hline Aspiration & 35 [9] & $8[5]$ & 0.09 \\
\hline Cardiac arrest & $5[1]$ & 4 [2] & 0.34 \\
\hline Transfusion & $1[0]$ & $0[0]$ & 0.27 \\
\hline
\end{tabular}

Baseline characteristics for ARDS patients who did not receive the PP, survivors and non-survivors. Values are expressed in percentages (\%) of total patients in the group or median with interquartile ranges [IQR], where applicable. kg, kilograms; PBW, predicted body weight; BMI, body mass index; APACHE, acute physiology and chronic health evaluation; ICU, intensive care unit; ARDS, acute respiratory distress syndrome.

Table S2 PP characteristics in survivors and non-survivors

\begin{tabular}{|c|c|c|c|}
\hline Characteristics & Survivors ( $\mathrm{N}=49)$ & Non-survivors $(\mathrm{N}=41)$ & $\mathrm{P}$ \\
\hline Time to first session, hours & 15 [5 to 50$]$ & $12[6$ to 31$]$ & 0.46 \\
\hline Number of sessions & $2[1$ to 2$]$ & $2[1$ to 2$]$ & 0.90 \\
\hline
\end{tabular}

Characteristics of the PP sessions. 
Table S3 Change in ventilation variables and parameters in survivors and non-survivors

\begin{tabular}{|c|c|c|c|c|}
\hline Variables and parameters & All & Survivors $(\mathrm{N}=49)$ & Non-survivors $(\mathrm{N}=41)$ & $\mathrm{P}$ \\
\hline PEEP, $\mathrm{cmH}_{2} \mathrm{O}$ & $0[-1$ to +3$]$ & $0[-1$ to +1$]$ & $+1[-1$ to +5$]$ & 0.12 \\
\hline $\mathrm{P}_{\max }, \mathrm{cmH}_{2} \mathrm{O}$ & $-1[-5$ to +6$]$ & $-4[-7$ to +3$]$ & $+1[-2$ to +7$]$ & 0.10 \\
\hline $\mathrm{FiO}_{2}, \%$ & $-20[-30$ to -5$]$ & $-20[-30$ to -5$]$ & $-15[-30$ to -5$]$ & 0.75 \\
\hline $\mathrm{PaCO}_{2}, \mathrm{mmHg}$ & $-4[-11$ to +2$]$ & $-4[-11$ to +1$]$ & $-5[-11$ to +6$]$ & 0.76 \\
\hline $\mathrm{HCO}_{3}^{-}, \mathrm{mmol} / \mathrm{L}$ & $-1[-2$ to +2$]$ & $+1[-2$ to +3$]$ & $-0.7[-3.7$ to +2.6$]$ & 0.66 \\
\hline $\mathrm{pH}$ & $+0.05[-0.02$ to +0.11$]$ & $+0.08[+0.03$ to +0.11$]$ & $+0.01[-0.05$ to +0.09$]$ & 0.02 \\
\hline $\mathrm{PaO}_{2} / \mathrm{FiO}_{2}$ & $+68[+21$ to +120$]$ & $+83[+24$ to +137$]$ & $+58[+21$ to +113$]$ & 0.30 \\
\hline
\end{tabular}

Change in variables and parameters before and after the first PP session. Data are expressed as median with IQR. VT, tidal volume; PBW, predicted body weight; PEEP, positive end-expiratory pressure; Pmax, maximum airway pressure; $\mathrm{FiO}_{2}$, fraction of inspired oxygen; $\mathrm{PaO}$, arterial oxygen tension; $\mathrm{PaCO}_{2}$, arterial carbon dioxide tension; $\mathrm{HCO}_{3}{ }^{-}$, arterial bicarbonate; $\mathrm{PaO}_{2} / \mathrm{FiO}_{2}$, ratio of arterial oxygen tension to fraction of inspired oxygen; $V_{D} / V_{T}$, dead space fraction; $\Delta P_{R S}$, respiratory system driving pressure.

Table S4 Univariate logistic regression

\begin{tabular}{|c|c|c|c|c|}
\hline Variables and parameters & Absolute change, OR $[95 \% \mathrm{Cl}]$ & $\mathrm{P}$ & Relative change, OR [95\% Cl] & $\mathrm{P}$ \\
\hline PEEP, $\mathrm{cmH}_{2} \mathrm{O}$ & $1.09[0.98$ to 1.21$]$ & 0.12 & $1.00[1.00$ to 1.00$]$ & 0.96 \\
\hline $\mathrm{P}_{\max }, \mathrm{cmH}_{2} \mathrm{O}$ & 1.06 [0.99 to 1.13$]$ & 0.10 & $1.01[0.99$ to 1.02$]$ & 0.42 \\
\hline $\mathrm{FiO}_{2}, \%$ & $1.00[0.97$ to 1.02$]$ & 0.75 & $1.00[0.98$ to 1.01$]$ & 0.71 \\
\hline $\mathrm{PaCO}_{2}, \mathrm{mmHg}$ & $1.04[0.83$ to 1.31$]$ & 0.74 & $1.01[0.99$ to 1.02$]$ & 0.51 \\
\hline $\mathrm{HCO}_{3}^{-}, \mathrm{mmol} / \mathrm{L}$ & $1.01[0.96$ to 1.07$]$ & 0.68 & $1.00[0.98$ to 1.01$]$ & 0.66 \\
\hline $\mathrm{pH}$ & $0.00[0.00$ to 0.58$]$ & 0.03 & 0.69 [0.49 to 0.95$]$ & 0.03 \\
\hline $\mathrm{PaO}_{2} / \mathrm{FiO}_{2}$ & $1.00[0.99$ to 1.00$]$ & 0.30 & 1.00 [0.99 to 1.00$]$ & 0.31 \\
\hline
\end{tabular}

Univariate logistic regression. Odds ratios are displayed for an increment of 1. OR, odds ratio; Cl, confidence interval; VT, tidal volume; PBW, predicted body weight; PEEP, positive end-expiratory pressure; Pmax, maximum airway pressure; $\mathrm{FiO}_{2}$, fraction of inspired oxygen; $\mathrm{PaO}_{2}$, arterial oxygen tension; $\mathrm{PaCO}_{2}$, arterial carbon dioxide tension; $\mathrm{HCO}_{3}{ }^{-}$, arterial bicarbonate; $\mathrm{PaO}_{2} / \mathrm{FiO}_{2}$, ratio of arterial oxygen tension to fraction of inspired oxygen; $\mathrm{V}_{\mathrm{D}} \mathrm{V}_{\mathrm{T}}$, dead space fraction; $\Delta \mathrm{P}_{\mathrm{RS}}$, respiratory system driving pressure. 
Table S5 Prognostic capacity of changes induced by the first PP session for ICU-mortality

\begin{tabular}{|c|c|c|c|c|c|c|}
\hline Parameters & AUROC (95\% Cl) & Best cutoff & Sensitivity (95\% Cl) (\%) & Specificity (95\% Cl) (\%) & PPV (\%) & NPV (\%) \\
\hline $\mathrm{PaO}_{2} / \mathrm{FiO}_{2}$ & 0.55 (0.43 to 0.67$)$ & $+68 \mathrm{mmHg}$ & 56 (34 to 70$)$ & 58 (38 to 74$)$ & 51 & 63 \\
\hline $\mathrm{V}_{\mathrm{D}} / \mathrm{V}_{\mathrm{T}}$ & 0.51 (0.39 to 0.64$)$ & -0.10 & 46 (27 to 55$)$ & 64 (51 to 78$)$ & 50 & 60 \\
\hline$\Delta \mathrm{P}_{\mathrm{RS}}$ & 0.61 (0.50 to 0.73$)$ & $-3 \mathrm{cmH}_{2} \mathrm{O}$ & 54 (33 to 72 ) & 63 (47 to 79$)$ & 56 & 73 \\
\hline $\mathrm{PaO}_{2} / \mathrm{FiO}_{2}$ & 0.54 (0.41 to 0.66$)$ & $+190 \%$ & 90 (71 to 99$)$ & 24 (11 to 36$)$ & 48 & 75 \\
\hline$V_{D} / V_{T}$ & $0.56(0.44$ to 0.68$)$ & $-44 \%$ & 85 (67 to 95) & 32 (19 to 46$)$ & 49 & 73 \\
\hline$\Delta \mathrm{P}_{\mathrm{RS}}$ & 0.59 (0.47 to 0.71$)$ & $-14 \%$ & 74 (54 to 87 ) & 48 (29 to 65$)$ & 53 & 71 \\
\hline
\end{tabular}

AUROC, area under the receiver operator characteristics curve; PPV, positive predictive value; NPV, negative predictive value; Cl, confidence interval; $\mathrm{PaO}_{2} / \mathrm{FiO}_{2}$, ratio between arterial oxygen tension and fraction of inspired oxygen; $\mathrm{V}_{\mathrm{D}} / \mathrm{V}_{\mathrm{T}}$, dead space fraction; $\Delta \mathrm{P}_{\mathrm{RS}}$, respiratory system driving pressure.

Table S6 Prognostic capacities of changes induced by the first PP session for 1-year mortality

\begin{tabular}{|c|c|c|c|c|c|c|}
\hline Parameters & AUROC (95\% Cl) & Best cutoff & Sensitivity (95\% Cl) (\%) & Specificity (95\% Cl) (\%) & PPV (\%) & NPV (\%) \\
\hline $\mathrm{PaO}_{2} / \mathrm{FiO}_{2}$ & $0.60(0.45$ to 0.75$)$ & $+68 \mathrm{mmHg}$ & 67 (46 to 82 ) & 68 (46 to 84$)$ & 64 & 70 \\
\hline $\mathrm{V}_{\mathrm{D}} / \mathrm{V}_{\mathrm{T}}$ & 0.54 (0.39 to 0.69$)$ & -0.11 & 70 (51 to 79$)$ & 48 (34 to 61$)$ & 54 & 65 \\
\hline$\Delta \mathrm{P}_{\mathrm{RS}}$ & 0.66 (0.52 to 0.81$)$ & $-3 \mathrm{cmH}_{2} \mathrm{O}$ & 63 (43 to 81$)$ & 77 (59 to 90) & 71 & 71 \\
\hline $\mathrm{PaO}_{2} / \mathrm{FiO}_{2}$ & 0.59 (0.44 to 0.74$)$ & $+75 \%$ & 63 (42 to 81$)$ & 65 (45 to 81$)$ & 61 & 67 \\
\hline $\mathrm{V}_{\mathrm{D}} / \mathrm{V}_{\mathrm{T}}$ & 0.54 (0.38 to 0.69$)$ & $-28 \%$ & 53 (36 to 73 ) & 63 (47 to 71$)$ & 54 & 62 \\
\hline$\Delta \mathrm{P}_{\mathrm{RS}}$ & 0.60 (0.48 to 0.73$)$ & $-13 \%$ & 55 (35 to 68$)$ & 71 (52 to 88 ) & 61 & 66 \\
\hline
\end{tabular}

AUROC, area under the receiver operator characteristics curve; PPV, positive predictive value; NPV, negative predictive value; Cl, confidence interval; $\mathrm{PaO}_{2} / \mathrm{FiO}_{2}$, ratio between arterial oxygen tension and fraction of inspired oxygen; $V_{\mathrm{D}} / V_{\mathrm{T}}$, dead space fraction; $\Delta \mathrm{P}_{\mathrm{RS}}$, respiratory system driving pressure. 